\title{
Impact of Media Breast Cancer Awareness Campaign on the Health Behaviour of Women in Southeast Nigeria
}

\author{
Joseph Oluchukwu Wogu ${ }^{1}$, Christiana Ogeri Chukwu ${ }^{2}$, Joel Chinedum Ugwuoke ${ }^{1}$, \\ Chinyere Christiana Ugwulor-Onyinyechi ${ }^{1} \&$ Chukwuemeka Ononuju Nwankiti ${ }^{2}$ \\ ${ }^{1}$ Department of Mass Communication, University of Nigeria Nsukka, P.M.B. 410001, Enugu State, Nigeria \\ ${ }^{2}$ Department of Mass Communication, Alex-Ekwueme Federal University, Ndufu-Alike Ikwo, P.M.B. 1010, \\ Abakaliki, Ebonyi State, Nigeria \\ Correspondence: Joel Chinedum Ugwuoke, Department of Mass Communication, University of Nigeria Nsukka, \\ P.M.B. 410001, Enugu State, Nigeria. Tel: 234-803-590-3791. E-mail: chinedum.ugwuoke@unn.edu.ng
}

Received: February 10, 2019 Accepted: April 7, 2019 Online Published: April 8, 2019

doi:10.5539/gjhs.v11n5p79 URL: https://doi.org/10.5539/gjhs.v11n5p79

\begin{abstract}
Objectives: The goals of the paper are to find out if there is any relationship between breast cancer preventive/curative measures and the contents of media campaign against it; ascertain if the media campaign established a high level of awareness among women; and examine the relationship between breast cancer awareness and the practice of preventive/curative behaviours.
\end{abstract}

Subjects \& Methods: The paper adopts a cross-sectional survey method that involves primary and secondary methods of data collection. Structured questionnaire was used to collect responses from women in relation to questions raised while published materials such as relevant books, journal articles, conference and workshop papers, and internet materials were reviewed to ascertain the current level and dimensions of research findings in the field across the world. Review of literature lasted for 8 weeks while distribution and collection of questionnaire lasted for 5 weeks. The study area is Southeast Nigeria, which comprises the five Igbo speaking states of Nigeria. A sample of 1000 women was randomly selected from markets, churches, schools, and civil service in the capitals of these states, i.e. Abakiliki, Awka, Enugu, Owerri, and Umuahia for the distribution of the structured questionnaire.200 questionnaires were distributed in each of the five study areas using multi stage random sampling technique with the aid of three research assistants. Their responses were tabulated and analysed using descriptive statistics in the SPSS version 20.0 tools.

Results: Results reveal a high level of breast cancer awareness although only $31.2 \%$ learnt of it through media campaign; the awareness did not orchestrate health behaviour modification among the respondents; while lack of appropriate knowledge of breast cancer disease, lack of fund and high cost of cancer treatment, and absence of accessible treatment facilities are the cause.

Conclusion: Media campaign against breast cancer in the Southeast Nigeria is deficient in terms of scope, reach, and contents. Secondly, poor standard of living and lack of appropriate corporate response to campaign and treatment of the disease are major problems. Therefore, modification of media contents and campaign programmes, together with government assisted breast cancer treatment mechanisms are recommended.

Keywords: breast cancer, curative and preventive, media, contents, awareness, and behaviour modification

\section{Introduction}

Breast Cancer is a common female terminal disease across the world and in every culture with more than 4.7million new cases reported annually. 55\% of this number occurs in Less Developing Countries (Adetifa \& Ojikutu, 2009). The spread of breast cancer has continued to increase at the rate 50-100\% globally (Hayam, Howida, \& Zakeya, 2014) and 0.5\% each year since 1985 in Nigeria (WHO, 2004). Nigeria records about 500,000 new cases yearly since 2010 with a dismal 10\% survival rate (Lambo, 2007; Salant et al., 2006). The Lagos State Ministry of Health observes that $15 \%$ of these cases occur in women less than 30 years, while majority of the cases occur at age range of 43-50 years (Oluwatosin, 2012; Adebamowo \& Ajayi, 2006).

Despite the growing campaigns on breast cancer awareness in Nigeria generally and Southeast particularly (Okobia, Bunker, Okonofua, et al., 2006), the rates of its spread tend to grow while the practice of required 
remedial practices continue to vary widely among women. Most of the rural women are either unaware of the cancer, have poor knowledge of breast cancer, or exhibit poor preventive and curative practices (Akpo, 2010; Makanguola, Amoo, Ajibade, et al., 2003). Consequently, civil society organisations, and relevant agencies in the Southeast Nigeria embarked on multiple media programmes using different radio channels, televisions, newspapers, and social media to create awareness of the cancer, its preventive and curative behaviours or measures. This paper investigates the phenomenon in Southeast with a view to the level and nature of awareness therein, and the associated influence on the health behaviour of women.

\subsection{Objectives of Study}

The primary objective of this inquiry is to evaluate the impact of media breast cancer awareness campaign on the health behaviour of women in Southeast Nigeria. However, its specific objectives are:

i. To find out if there is any relationship between breast cancer preventive/curative measures and the contents of media campaign against it.

ii. To ascertain if the media campaign established a high level of awareness among women.

iii. To examine the relationship between breast cancer awareness and the practice of preventive/curative behaviours.

\subsection{Study Significance and Literature Review}

The study will enable relevant agencies concerned with eradicating breast cancer in Southeast Nigeria and Nigeria in general to appraise the cancer media campaign, its contents, and framework for possible modification. The finding is expected to provide information to health care providers that will shape their education and awareness programmes on breast cancer. It shall identify the problems limiting the success of the media campaign. The information obtained from this study may be of help to other researchers interested in working in this field as it will serve as a reference material for further research. Numerous researches reveal that the major causes of breast cancer in women are blood lineage, pre-12 years menstruation, menopause after 55 years, old age, post 30 years first pregnancy, infertility, use of contraceptives, hormonal treatment after menopause, no history of breast feeding, overweight and obesity, excessive exposure to ionizing radiations before 30 years of age, hormonal dysfunction, stress and unhealthy lifestyle (Obaji, Elom, Agwu, Nwigwe, Ezeonu, \& Umeora, 2013; Arif, Al-Saif, Al-Karrawi, \& Al-Sagair, 2011). Others observe that lack of knowledge/awareness and resources, absence of regular test/screening, lack of effective screening and treatment strategies, late presentation and treatment of patients appear to exacerbate its spread and increase the death rate (Ojong, Etim, Samson-Akpan, et al., 2013; Akpo, 2010) As a panacea to combating cancer, the Nigeria Federal Government began to establish diagnostic/treatment centres, acquire medical treatment facilities, and drew a National Cancer Policy with strategic framework to implement it (Lambo, 2007). Relevant agencies and Civil Society Organisations such as Care Organization Public Enlightenment (COPE), Bloom Cancer Care and Support Services, etc initiated cancer awareness campaign across Nigeria to sensitize women about the cancer, its prevention, government policy and the availability of treatment schemes/facilities. Scholars suggest that creating breast cancer awareness, preventive health behaviour such as breast self-examination and early screening, educational empowerment of women, and medical assistance as solutions to breast cancer (Virginia, 2012; Salati \& Rather, 2009).

Consequently, in a study to determine the level of awareness, attitude and practice of rural women regarding breast cancer in Southeast Nigeria using 1,600 rural women aged 20 to 60 years, Onwere, Okoro, and Chigbue, et al. (2009) observed that $58.2 \%$ of them are aware of the scourge but lack appropriate knowledge of its cause, symptoms, prevention and medical treatment. This research failed to investigate or analyse the medium and contents of the cancer awareness programme to find out if it is the cause of the observed ignorance. Similarly, the investigation conducted by Jebbin and Adotey (2009) on the level of awareness, attitude to, knowledge and practice of preventive/curative measures among women residents in Port Harcourt city, South-south Nigeria reveals that women are aware of the scourge and its preventive measures but fail to practice them. The inquiry equally failed to identify the medium and content of the awareness programme, and the reasons why the women did not practice the preventive/curative measures.

The study by Okobia, Bunker, Okonofua and Osime (2006) equally revealed poor knowledge of breast cancer among Nigerian women. However, the result further shows that majority of the women are willing to participate in the awareness programme and engage in positive health behaviour modification. Similarly, in their study on rural women of Ibadan, Nigeria Oluwatosin and Oladepo (2006) observed that $73.7 \%$ of the respondents are ignorant of symptoms of breast cancer and the mechanisms for practicing self-examination. Another study by Alam (2006) for rural women in Port Harcourt, and that conducted by Amosu, Adegun, Thomas and Babalola (2011) among rural 
women in Ipokia Local Government Area, Ogun State, Nigeria revealed similar result.

Nevertheless, scholars like Okorie and Abiodun (2016),Okorie, Oyesomi, Olusola, Olatunji and Soola (2014); Kreps and Sivaram (2009); and Okorie (2011) argue that in the sphere of human health management, sources of information and campaign programmes are essential for health promotion. This is because media awareness campaigns 'are varied, multifaceted, highly planned and strategically assembled media symphonies designed to increase awareness, inform, or change behaviour in target audiences" (Day, 2011:79). The campaigns are designed to suit the behaviours and environments of target groups in order to tackle diseases and health challenges, and are influential in motivating attitudinal change.

In this regard, Kreps and Sivaram (2009) and Okorie (2011) acknowledged the efficaciousness of mass media outlets in the campaigns to promote breast cancer prevention and care. A study conducted by Irurhe, Raji, Olowoyeye, Adeyomoye, Arogundade, Soyebi, Ibitoye, Abonyi and Eniyandunni (2012) on knowledge and awareness of breast cancer among female secondary students in Nigeria reveals that $97 \%$ of the respondents heard of breast cancer through the media. Breast cancer has formed the main theme of media programmes both in Nigeria and abroad (Al-Naggar \& Jashamy, 2011; Cohen, Caburnay, Luke, Kreuter, Cameron, \& Rogers, 2006).An analysis of these reviews reveals that researchers are more interested in assessing knowledge, awareness and attitude but failed to assess media contribution to the awareness, reasons for poor knowledge or awareness of the people, the content of the media awareness campaigns, and the impact of the awareness on the health behaviour of women particularly in the Southeast, Nigeria. This paper fills this lacuna.

\subsection{Theoretical Review}

This study adopts the agenda setting theory and the framing theory as its framework of analysis. The main proposition of the Agenda setting theory is that the media has the ability to transfer issues of importance from media agendas to public agendas and thereby influence people's perceptions on what should constitute the most important issues of the day (Ogbuoshi, 2011; Folarin, 1998). Thus, the media can make cancer preventive/curative programme a public agenda through its contents (Kalu, 2010). It stimulates people's interest through idea framing - the framing theory. The basic principle of framing theory is that the media focuses attention on certain events and then places them within a field of meaning. The media organizes and presents events and issues in the way audiences interpret what they imply (Asemah, 2011). In this case, how an issue is presented (the frame) influences the choices people make. This affects people's beliefs, attitudes and behaviours because it connects a particular meaning or interpretation to an issue. Here the media connects the meaning and consequences breast cancer, and associated preventive practices to women mortality. These two theories provide the framework adopted by this paper to assess the impact of the media cancer awareness campaign on the health behaviour modification of women in Southeast Nigeria.

\section{Subjects and Methods}

Geographically, the study covers the five states of the Southeast. Thematically, the study investigates the level awareness of breast cancer in states studied, the nature of media campaign driving the awareness and their impact on behaviour modification. This is not a periodic study because it deals with life experience. Consequently, it adopts a cross-sectional survey of the five states of the Southeast Nigeria. Due to the overwhelming landmass and population of people in Southeast Nigeria, the capitals of these states, i.e. Abakiliki, Awka, Enugu, Owerri, and Umuahia are selected as areas of study. Primary and secondary sources of data were explored. In the primary source, structured questionnaire in five-point Likert scale format was used to collect primary data from a sample of 1000 women randomly selected from markets, churches, schools, and civil service. 200 questionnaires were distributed in each of the five study areas while multi stage random sampling technique was used to select respondents in the target areas. In a period of five weeks, the questionnaires were administered by three research assistants, who interpreted same in local language (Igbo language) to those who were non-literate, and all questionnaires were retrieved from the respondents. To complement the primary data, data were equally collected from secondary sources. In the secondary source, the researcher consulted books, journals, conference and workshop papers, newspapers, magazines, and government gazettes as can be found in public and private libraries, and the internet for secondary data. Experts in the Faculties of Arts and Social Sciences University of Nigeria were asked to assess the relevance of the contents and tools used, and test the validity of the instrument used for data collection. Further, a test-retest method was carried out within an interval of two weeks in three towns of Enugu state to test its reliability. An analysis of the reliability coefficient of the research instrument was estimated to be 0.95 using Cronbach's Alpha technique. The data generated during the research was analysed using percentage and analysis of variance (ANOVA) with the aid of SPSS, version 20.0. 


\section{Results}

An analysis of respondents' age groupings reveals that $14.5 \%$ are within $15-35$ years i.e. 145 respondents; $47 \%$ are within $36-45$ years i.e. 470 respondents; $27.5 \%$ are within $46-60$ years i.e. 275 respondents; while $11 \%$ representing 110 respondents are within the ages of 60 years and above. Further, investigation into the educational attainment of the respondents reveals that $44.3 \%$ representing 443 respondents acquired secondary/high school education, $17.4 \%$ of the respondents i.e. 174 obtained non-formal education, $29.6 \%$ representing 296 respondents acquired only primary education, while 87 respondents i.e. $8.7 \%$ acquired tertiary education. Occupationally, the analysis equally reveal that $14.5 \%$ of the respondents i.e. 145 are Civil Servants, $46.4 \%$ representing 464 respondents are traders, $33.3 \%$ of the respondents i.e. 333 are farmers and self-employed, while $5.8 \%$ representing 58 respondents are house wives. Equally, inquiry into the marital status on the respondents reveals that 188 respondents i.e. $18.8 \%$ are single, $58 \%$ representing 580 respondents are married, $8.7 \%$ i.e. 87 respondents are widows, while $14.5 \%$ of the respondents i.e. 145 are divorced. A review of the above demographic data statistics shows that the respondents are appropriate, spatially and fairly distributed among the female folk, ought to possess the requisite knowledge and experience on the subject of investigation. Therefore, they are the appropriate target of breast cancer media awareness campaign and for the study. The SPSS univariate analysis of responses to questions interrogating women's awareness of breast cancer disease reveals a total grand mean of 4.21 with a standard error of .032 and a standard deviation of 1.063. The confidence interval of the responses lies between 4.152 and 4.276. According to its Tests of Between-Subjects Effects in Table 1, the mean differences of the entire responses show a significant difference $(P=.000)$.

Table 1. Tests of between-subjects effects

\begin{tabular}{llllll}
\hline Dependent Variable: Responses & & & & \\
\hline Source & Type III Sum of Squares & Df & Mean Square & F & Sig. \\
\hline Corrected Model & $122.054^{\mathrm{a}}$ & 4 & 30.513 & 30.175 & .000 \\
Intercept & 17757.796 & 1 & 17757.796 & 17561.007 & .000 \\
Southeast & 122.054 & 4 & 30.513 & 30.175 & .000 \\
Error & 1006.150 & 995 & 1.011 & & \\
Total & 18886.000 & 1000 & & & \\
Corrected Total & 1128.204 & 999 & & & \\
\hline
\end{tabular}

a. R Squared $=.108($ Adjusted R Squared $=.105)$.

The analysis further reveals that $31.2 \%$ i.e. 312 respondents learnt about breast cancer through radio and TV programmes, 403 respondents representing $40.3 \%$ learnt about it through antenatal clinics and civil society campaign, 188 respondents i.e. $18.8 \%$ got their own information from the print media, while 97 respondents representing 9.7\% have no idea about breast cancer. On the impact of breast cancer public education program over time, the analysis of response to the questions of what they call breast cancer in their days of ignorance and methods of treating it, entire 789 respondents representing $78.9 \%$ said that people called it poisonous attack from enemies, while 211 respondents representing $21.1 \%$ termed it punishment from the gods. Consequently, the first set that consider it poisonous attack resort to different forms of herbal treatments while those that consider it spiritual punishment resort to purifications and ritual sacrifices. Both approaches fail to prevent the terminal nature of the disease as patients die in agony. However, the univariate analysis of their responses to the question of attending or performing clinical breast cancer examination by health workers reveals a total grand mean of 2.23 with a standard error of .023 and a standard deviation of .762. The confidence interval of the responses lies between 2.183 and 2.273. According to its Tests of Between-Subjects Effects in Table 2 below, the mean differences of the entire responses shows a significant difference $(P=.000)$. 
Table 2.Tests of Between-Subjects Effects

Dependent Variable: Responses

\begin{tabular}{llllll}
\hline Source & Type III Sum of Squares & df & Mean Square & F & Sig. \\
\hline Corrected Model & $49.326^{\mathrm{a}}$ & 4 & 12.331 & 23.121 & .000 \\
Intercept & 4963.984 & 1 & 4963.984 & 9307.061 & .000 \\
Southeast & 49.326 & 4 & 12.331 & 23.121 & .000 \\
Error & 530.690 & 995 & .533 & & \\
Total & 5544.000 & 1000 & & \\
Corrected Total & 580.016 & 999 & & \\
\hline
\end{tabular}

a. R Squared $=.085$ (Adjusted R Squared $=.081)$

In Table 2, further analysis of the factors responsible for women's observed attitudes to cancer preventive and curative measures shows that lack of appropriate knowledge of the nature, consequences and curative measures of breast cancer has a total grand mean of 4.04, a standard error of .038 and a standard deviation of 1.264. The confidence interval of the responses lies between 3.969 and 4.119. Its Tests of Between-Subjects Effects reveals that the mean differences of the entire responses shows a significant difference $(P=.000)$. Similarly, analysis of responses to the statement that lack of fund/high cost of treatment influenced women's attitudes to cancer preventive and curative measures reveals a total grand mean of 4.21 with a standard error of .071 , and a standard deviation of 1.063.The confidence interval of the responses lies between 4.152 and 4.276. Its Tests of Between-Subjects Effects reveals that the mean differences of the entire responses shows a significant difference $(P=.000)$. Equally, analysis of responses to the statement that lack of accessible breast cancer facilities influenced women's attitudes to cancer preventive and curative measures reveals a total grand mean of 4.00 and a standard deviation of .891. The confidence interval of the responses lies between 3.94 and 4.05. Its Tests of Between-Subjects Effects reveals that the mean differences of the entire responses shows a sig. Difference $(P$ $=.000)$.

\section{Discussion}

This paper investigated the impact of media Breast Cancer Awareness Campaign on the Health Behaviour of Women in Southeast Nigeria. In pursuit of this objective, the paper investigated the level of women's awareness of breast cancer disease, which reveals a total grand mean of 4.21 with the mean differences of the entire responses showing a sig. difference. The grand mean response of 4.21 representing 'Agreed' in our likert scale measure was accepted. This implies that the majority of the respondents are aware of breast cancer disease. According their responses, majority of them received the knowledge through antenatal clinics and civil society campaign (40.3\%), and radio/TV programmes $(31.2 \%)$.

However, in spite of the acknowledged awareness of breast cancer disease, analysis of their responses to the question of whether they attend or perform clinical breast cancer examination reveals a total grand mean of 2.23 with the mean differences of the entire responses shows a significant difference. The grand mean response of 2.23 representing 'Disagreed' was accepted. This implies that majority of the respondents do not attend or perform clinical breast cancer examination.

It must be observed here that although majority of respondents do not attend or perform clinical breast cancer examination, there are some, which are in the minority that attend the clinical services. This is an indication that the campaign or breast cancer public education has positive but gradual impact on women's health behaviour modification overtime. The analysis of responses to questions that interrogated the cause of or the factors responsible for this low impact reveals that lack of appropriate knowledge of the nature, consequences and curative measures of breast cancer with a total grand mean of 4.04, and mean differences of the entire responses showing a significant difference imply that it is one of the factors responsible for their non-participation in clinical breast cancer examination and preventive/curative treatments. The grand mean response of 4.04 representing 'Agreed' was accepted, and implies that lack of appropriate knowledge of the nature, consequences and curative measures of breast cancer prevents women health behaviour modification in Southeast Nigeria.

The analysis also reveals a total grand mean of 4.21 with mean differences of the entire responses showing a significant difference for responses to the statement that lack of fund and high cost of cancer treatment militate against women engagement in cancer preventive and curative measures in Southeast Nigeria. The grand mean 
response of 4.21 representing 'Agreed' was accepted, and implies that lack of fund and high cost of cancer treatment prevents women health behaviour modification in Southeast Nigeria. The analysis also reveals a total grand mean of 4.00 with the mean differences of the entire responses to the statement that lack of accessible breast cancer facilities militates against women involvement in cancer preventive and curative measures showing a significant difference. The grand mean response of 4.00 representing 'Agreed' was accepted, and implies that lack of accessible breast cancer facilities also militates against women health behaviour modification in Southeast Nigeria. Apart from the available minimal breast cancer treatment women receive in University of Nigeria Teaching Hospital Enugu (UNTH), none of the specialised breast cancer facilities is located in any of the Southeast states. People travel to University Teaching Hospital Ibadan for diagnosis and treatments.

The key findings made by the above analysis are:

1) Majority of the Southeast women are aware of the breast cancer disease.

2) Antenatal clinics, civil society campaign and radio/TV campaign programmes are the major sources of information concerning breast cancer disease.

3) Majority of Southeast women do not attend or perform clinical breast cancer examination. However, considering the people's response to the disease before the public education programme, and the fact that some respondents, although in the minority, attend breast cancer clinical services now, there is low health behaviour modification among Southeast women in spite their assumed knowledge of the disease.

4) Lack of appropriate knowledge of the nature, consequences and curative measures of breast cancer disease contributes to the observed women low health behaviour modification in Southeast Nigeria.

5) Lack of fund and high cost of cancer treatment hinder the participation of Southeast women in breast cancer preventive and curative measures.

6) Absence of accessible Breast Cancer Treatment Facilities also militates against women's participation in breast cancer preventive and curative measures in Southeast Nigeria.

The implication of these findings in the context of existing research is complementary and recommends modification of media breast cancer campaign and programmes. These findings concur with previous studies in the areas of media role in creating breast cancer awareness but unlike them, highlight the inadequacy of the media campaign and content, and the inability of women to access Breast Cancer Treatment Facilities due to some factors. However, this study is limited in thematic scope to investigate the nature of Breast Cancer Treatment Facilities available, their adequacy, constraints and their solutions.

\section{Conclusions}

After due consideration of these findings, this paper concludes that inappropriate media awareness campaign and knowledge of the nature, consequences and curative measures of breast cancer disease, lack of fund/poverty, high cost of treatments, and absence of accessible breast cancer treatment facilities are the major factors responsible for low but gradual health behaviour modification among women and the spread of breast cancer disease in Southeast Nigeria. The relevance of this conclusion lies on the high level of breast cancer infections in the Southeast, and its request for the re-evaluation and modification of media contents and public education programmes as precursor to proper women health behaviour modification in the area. This paper, therefore, recommends appropriate modification of media campaign contents and programmes to incorporate the nature, signs, consequences and curative measures of breast cancer. Secondly, each state government in the Southeast should urgently establish free breast cancer examination, detective and treatment centre as part of their corporate social responsibility. In addition, government should introduce a health policy that makes it compulsory for women to attend clinical breast cancer examination and engage in preventive health behaviour modification across the Southeast. Thirdly, relevant organs of United Nations, international Non-governmental Organisations, and the African Union should provide assistance to enable these states provide this assistance and services.

\section{Ethics Approval and Consent to Participate}

Appropriate Ethics approval and Consent of the respondents to participate in the research were obtained after detailed explanation of the intent of the research, guarantee of individual anonymity were given. We hereby authorise and consent to the publication of this paper if accepted.

\section{Funding}

None. 


\section{Authors' Contributions}

Authors contributed equally in all aspect of this research.

\section{Competing Interests Statement}

The authors declare that there are no competing or potential conflicts of interest.

\section{References}

Adebamowo, C. A., \& Ajayi, C. (2006). Breast Cancer in Nigeria.West African Journal of Medicine, 19, 179-171

Adetifa, F. A., \& Ojikutu, R. K. (2009). Prevalence and Trends in Breast Cancer in Lagos State, Nigeria. African Research Review, 3(5), 1-15.

Akpo, E. E. (2010). Breast cancer knowledge and screening practices among Nigerian medical students. Internet Journal of Health, 11(2), 6-9

Al-Naggar, R. A., \& Al-Jashamy, K. (2011). Breast cancer coverage in the media in Malaysia. A qualitative content analysis of Star newspaper articles. Asian Pacific Journal of Cancer Prevention, 12, 564-672.

Amosun, A., Degun, A., Thomas, A., \& Babalola, A. (2011). Assessment of awareness perception, specific knowledge and screening behaviour regarding breast cancer among rural women in IpokiaLGA. Archives of Applied Science Research, 9(2), 253-265

Arif, J., Al-Saif, A., Al-Karrawi, C., \& Al-Sagair, O. (2011). Causative relationship between diabetes mellitus and breast cancer in various regions of Saudi Arabia: An Overview. Asian Pacific Journal of Cancer Prevention, $12,589-592$.

Asemah, E. S. (2011). Mass media in the contemporary society. Jos: University press

Cohen, E. L., Caburnay, C. A., Luke, D., Kreuter, M. N., Cameron, G. T., \& Rogers, S. (2006). Evidence of health disparities in cancer coverage of African American communities. Paper presented at the annual meeting of the International Communication Association; Dresden, Germany.

Folarin, B. (1998). Theories of mass communication. Ibadan, Nigeria: Sceptre Publishing ltd.

Hayam, E., Howida, A., \& Zakeya, B. (2014). Effect of Health Education on Raising Female Students Awareness Regarding Breast Cancer at Saudi Arabia. Journal of Natural Sciences Research, 4(9), 32-41.

Jebbin, N. J., \& Adotey, J. M. (2009). Attitude to knowledge and practice of breast self examination in Port Harcourt. Nigeria Journal of Medicine, 13(2), 166-170.

Kalu, L. E. (2010). The media and political communication in Nigeria. Journal of Media and Political Studies, 2(1), 1-12.

Kreps, G., \& Sivaram, R. (2009). Strategic health communication across the continuum of breast cancer care in limited resource countries. Cancer Supplements, 113(8), 2331-2337.

Lambo, E. O. (2007). Press Release on State of Health in Nigeria. Retrieved from http://www.health.gov.ng/index.php/news-media/press-releases

Obaji, N. C., Elom, H. A., Agwu, U. M., Nwigwe, C. G., Ezeonu, P. O., \& Umeora, O. U. (2013). Awareness and Practice of Breast Self-Examination among Market Women in Abakaliki, South East Nigeria. Annals of Medical and Health Sciences Research, 3(1), 7-12. https://doi.org/10.4103/2141-9248.109457

Ogbuoshi, L. I. (2011). Introduction to mass communication. Enugu: Newmoon Publishers

Ojong, I. N., Etim, P. E., Samson-Akpan, P. E., et al. (2013).Utilization of cervical cancer screening services by women of childbearing age in Uyo Metropolis, AkwaIbom State. Mary Slessor Journal of Medicine, 12(1), 24-32.

Okobia, M. N., Bunker, C. H., Okonofua, F. E., et al. (2006). Knowledge, attitude and practice of Nigerian women towards breast cancer: A cross sectional study. World Journal of Surgical Oncology, 21(4), 1-9.

Okorie, N. (2011). Development journalism and Africa: Tackling violence against women. Africana, 5(2), 171-184.

Okorie, N., \&Abiodun, S. (2016). Effective Use of Media Awareness Campaigns for Breast Cancer Care among Women: A Comparative Study. Journal of International Women's Studies, 17(4), 160-173.

Okorie, N., Oyesomi, K., Olusola, O., Olatunji, R. W., \& Soola, E. O. (2014). Effective Use of Information Sources for Breast Cancer Care: Interplay of Mass Media and Interpersonal Channels. Journal of African 
Research in Business and Technology, 1, 1-12

Salant, T., Ganschow, P. S., Olopade, O. I., \& Lauderdale, D. S. (2006). Why Take it if you don't Have Anything? Breast Cancer Risk Perceptions and Prevention Choices at a Public Hospital. Journal of General Internal Medicine, 21(7), 779-785. https://doi.org/10.1111/j.1525-1497.2006.00461.x

Oluwatosin, O. (2012). Primary Health care nurses' knowledge, practice and client teaching of early detection measures of breast cancer in Ibadan. BMC Nursing, 11, 1-8. https://doi.org/10.1186/1472-6955-11-22

Oluwatosin, O. A., \& Oladepo, O. (2006). The level of the knowledge of breast cancer and it's early detection measures among rural women in Akinyele local area Ibadan, Nigeria. BMC Cancer, 6, 271. https://doi.org/10.1186/1471-2407-6-271

Onwere, S., Okoro, O., Chigbue, B., et al. (2009).Breast self-examination as a method of early detection of breast cancer: KAP among antenatal clinic attendees in South Eastern Nigeria. Pak Journal Medical Science, 25(1), $122-125$.

Onyebuchi, C. (2012). Are cancers cases increasing in Nigeria?' The National Line, 2(1), 11-18.

Salati, S. A., \& Rather, A. (2009).Awareness regarding female breast cancer in Kashmiri males. Journal of Health and Allied Sciences, 8(4), 1-11

Virginia, O. (2012). Breast self-examination among female undergraduates in Enugu, Southeast, Nigeria. International Journal of Nursing and Midwifery, 4(1), 1-7.

\section{Copyrights}

Copyright for this article is retained by the author(s), with first publication rights granted to the journal.

This is an open-access article distributed under the terms and conditions of the Creative Commons Attribution license (http://creativecommons.org/licenses/by/4.0/). 